\title{
SpiroLactams4Life - Novas Espiro- $\beta$ - lactamas com Atividade Antimicrobiana Potente: Uma Nova Arma para o Tratamento de Infeções por HIV e Malária \\ Vasco Bonifácio \\ vasco.bonifacio@tecnico.ulisboa.pt
}

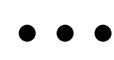

De acordo com a ONU, no final de 2019 aproximadamente 38 milhões de pessoas estavam infetadas com HIV-1 e HIV-2. Este vírus continua a ser a causa de morte de aproximadamente 1 milhão de pessoas todos os anos. Por outro lado, a malária é causada por parasitas do género Plasmodium, fazendo anualmente aproximadamente quatrocentas mil vítimas mortais. A existência de grande sobreposição geográfica da incidência destas infeções, em particular na África Subsariana, leva a que a coinfeção se torne bastante comum. Os dois agentes microbianos estabelecem uma sinergia em que ambas as patologias se potenciam mutuamente, levando a um aumento do risco de transmissibilidade assim como de desenvolvimento de infeções mais severas. As infeções por HIV e por malária são tratadas com fármacos específicos para cada uma das doenças, existindo preocupações relativamente a interações fármaco-fármaco indesejáveis. Neste contexto, a descoberta de novos princípios ativos com atividade potente contra ambos os agentes infeciosos é particularmente relevante.

Os estudos realizados por uma equipa interdisciplinar levaram à descoberta de novas espiro- $\beta$-lactamas com notável atividade contra o HIV e o Plasmodium (fase hepática e sanguínea). A molécula mais promissora, além de inibir o HIV-1 e o HIV-2, com valores de IC I0 $_{50}$ $\mathrm{nM}$ e $8 \mathrm{nM}$, respetivamente, também mostrou ser ativa contra estirpes multirresistentes. Provou, igualmente, ser ativa contra a infeção hepática por $P$. berghei $\left(I C_{50}\right.$ $=0,55 \mu \mathrm{M})$ e sanguínea por P. falciparum $\left(\mathrm{IC}_{50}=0,43\right.$ $\mu \mathrm{M})$. Novos desenvolvimentos sugerem a existência de um mecanismo de ação novo e complexo. 0 trabalho de investigação está agora focado no estudo mais aprofundado do mecanismo de ação desta nova classe de compostos espiro- $\beta$-lactâmicos, na caracterização das suas propriedades farmacocinéticas e farmacodinâmicas, e na avaliação da sua atividade in vivo. 0 estudo da atividade destes compostos contra outros vírus será igualmente uma prioridade desta equipa de investigaação.
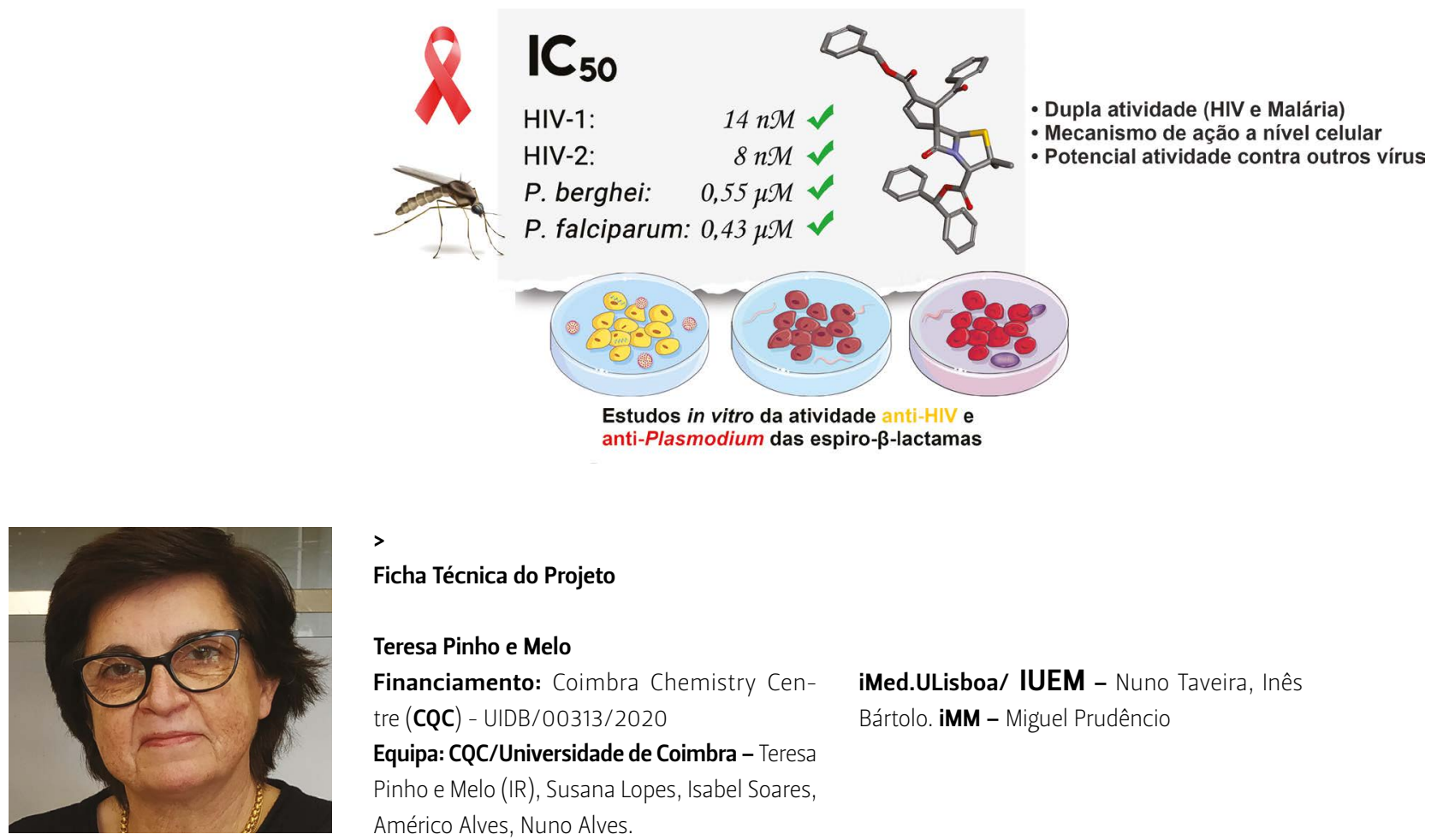

Ficha Técnica do Projeto

Teresa Pinho e Melo

Financiamento: Coimbra Chemistry Centre (CQC) - UIDB/00313/2020

Equipa: CQC/Universidade de Coimbra - Teresa

Pinho e Melo (IR), Susana Lopes, Isabel Soares,

Américo Alves, Nuno Alves.
iMed.ULisboa/ IUEM - Nuno Taveira, Inês Bártolo. iMM - Miguel Prudêncio 